\title{
Progressive Cortical Neuronal Damage and Extracranial- Intracranial Bypass Surgery in Patients with Misery Perfusion
}

\author{
(D) H. Yamauchi, DS. Kagawa, (D). Kishibe, (D) M. Takahashi, and DT. Higashi
}

\begin{abstract}
BACKGROUND AND PURPOSE: Misery perfusion may cause selective neuronal damage in atherosclerotic ICA or MCA disease. Bypass surgery can improve misery perfusion and may prevent neuronal damage. On the other hand, surgery conveys a risk for neuronal damage. The purpose of this retrospective study was to determine whether progression of cortical neuronal damage in surgically treated patients with misery perfusion is larger than that in surgically treated patients without misery perfusion or medically treated patients with misery perfusion.
\end{abstract}

MATERIALS AND METHODS: We evaluated the distribution of benzodiazepine receptors twice by using PET and "C-labeled flumazenil in 18 surgically treated patients with atherosclerotic ICA or MCA disease ( 9 with misery perfusion and 9 without) and no perioperative stroke before and after bypass surgery; in 8 medically treated patients with misery perfusion and no intervening ischemic event; and in 7 healthy controls. We quantified abnormal decreases in the benzodiazepine receptors of the cerebral cortex within the MCA distribution and compared changes in the benzodiazepine receptor index among the 3 groups.

RESULTS: The change in the benzodiazepine receptor index in surgically treated patients with misery perfusion (27.5 \pm 15.6$)$ during $7 \pm 5$ months was significantly larger than that in surgically treated patients without misery perfusion $(-5.2 \pm 9.4)$ during $6 \pm 4$ months $(P<.001)$ and in medically treated patients with misery perfusion $(3.2 \pm 15.4)$ during $16 \pm 6$ months $(P<.01)$.

CONCLUSIONS: Progression of cortical neuronal damage in surgically treated patients with misery perfusion and no perioperative stroke may occur and may be larger than that in medically treated patients with misery perfusion and no intervening ischemic event.

ABBREVIATIONS: $\mathrm{BZR}=$ benzodiazepine receptor; $\mathrm{CMRO}_{2}=$ cerebral metabolic rate of oxygen; $\mathrm{FMZ}=$ flumazenil; $\mathrm{FMZ}-\mathrm{BP}=$ flumazenil-binding potential; $\mathrm{MP}=$ misery perfusion; $\mathrm{OEF}=$ oxygen extraction fraction

C hronic hemodynamic impairment, as indicated by an increased oxygen extraction fraction (OEF; misery perfusion $[\mathrm{MP}])^{1}$ on PET, is a risk factor for subsequent ischemic stroke in patients with atherosclerotic ICA or MCA occlusive diseases. ${ }^{2-4}$ Furthermore, MP is thought to cause cognitive impairment independent of infarction. ${ }^{2,5}$ Extracranial-intracranial bypass surgery

Received October 18, 2016; accepted after revision December 17.

From the Division of PET Imaging (H.Y., S.K., Y.K., M.T., T.H.), Shiga Medical Center Research Institute, Moriyama, Japan; and National Institute of Radiological Sciences (T.H.), National Institutes of Quantum and Radiological Science and Technology, Chiba, Japan.

This study was funded by the Japan Society for the Promotion of Science Grantsin-Aid for Scientific Research, grant No. 26461323 and 22613001

None of the funding sources had any involvement in the design of the study or in the collection, analysis, and interpretation of the data.

Please address correspondence to Hiroshi Yamauchi, MD, Division of PET Imaging, Shiga Medical Center Research Institute, 5-4-30 Moriyama, Moriyama 524-8524, Japan; e-mail: yamauchi@res.med.shiga-pref.jp

- Indicates open access to non-subscribers at www.ajnr.org

http://dx.doi.org/10.3174/ajnr.A5110 has been demonstrated to improve MP. ${ }^{1,6}$ However, whether bypass surgery improves stroke risk or cognitive impairment in patients with MP is controversial. $^{7-10}$

The Carotid Occlusion Surgery Study of patients with recently symptomatic ICA occlusion and MP failed to show that bypass surgery compared with medical therapy reduced the risk of ipsilateral ischemic stroke at 2 years. ${ }^{9}$ Furthermore, the Randomized Evaluation of Carotid Occlusion and Neurocognition trial, an ancillary study of the Carotid Occlusion Surgery Study, showed that bypass compared with no bypass did not lead to improved cognitive function after 2 years in patients with no recurrent stroke. ${ }^{8}$ However, in the Carotid Occlusion Surgery Study, the perioperative stroke rate was sufficiently high to nullify any benefit. Therefore, the study was criticized for the possibility that patients with MP in the bypass group may also have experienced deleterious effects on cognition (ie, silent stroke), which overshadowed any beneficial effects of improved cerebral perfusion. ${ }^{11}$ However, no study has investigated silent stroke after bypass surgery in patients with MP, to our knowledge. 
MP may cause not only cerebral infarction but also selective neuronal damage in the cerebral cortex that is not detectable as an infarction on CT or MR imaging. ${ }^{12}$ Because most cortical neurons express central-type benzodiazepine receptors (BZRs), specific imaging of these receptors has made possible the in vivo visualization of neuronal alterations induced by ischemia. ${ }^{12-14}$ Selective neuronal damage can be detected in humans by using PET and ${ }^{11} \mathrm{C}$-labeled flumazenil, a neuronal tracer. ${ }^{15,16}$ Bypass surgery can improve MP and may prevent neuronal damage. Conversely, surgery conveys a risk of selective neuronal damage. However, no study has investigated changes of BZRs after bypass surgery in patients with or without MP. Carotid endarterectomy for patients with chronic hemodynamic impairment was found to result in a decrease in BZRs that was correlated with postoperative cognitive impairment associated with cerebral hyperperfusion or ischemia. ${ }^{17}$ If this result is also the case in bypass surgery, the progression of neuronal damage in surgically treated patients with MP should be compared with that in medically treated patients with $\mathrm{MP}$, in order for the procedure to prevent neuronal damage.

The purpose of this retrospective study was to determine whether the progression of cortical neuronal damage, evaluated as a decrease in BZRs, in surgically treated patients with MP is larger than that in surgically treated patients without MP or medically treated patients with MP.

\section{MATERIALS AND METHODS \\ Patients}

We retrospectively analyzed data collected from 18 surgically treated patients and 8 medically treated patients enrolled in an observational study that investigated the relationship between hemodynamic compromise and selective neuronal damage in patients with atherosclerotic occlusive disease of the ICA or MCA. Patients were referred to our PET unit from 2002 to 2013 for evaluation of the hemodynamic effects of ICA or MCA disease as part of a comprehensive clinical evaluation to determine the necessity of vascular reconstruction surgery.

Using PET before and after bypass surgery (anastomosis of superficial temporal artery branch to a MCA cortical branch), we studied 18 patients (12 men and 6 women; mean age, $59 \pm 10$ years) with atherosclerotic occlusion or stenosis of the ICA or MCA (Table 1). The interval between baseline and follow-up PET studies ranged from 2 to 16 months (mean, $6 \pm 4$ months). The interval between bypass surgery and follow-up PET ranged from 1 to 14 months (mean, $5 \pm 4$ months). Four patients with MP and 4 patients without MP were part of a previously published dataset. $^{16}$

Inclusion criteria for the present study were as follows: 1) occlusion of the extracranial ICA or occlusion or stenosis $(>50 \%$ diameter reduction) of the intracranial ICA or MCA as documented by conventional or MR angiography ${ }^{18}$; 2) functional independence in daily life (a modified Rankin Scale score of $<3$ ); 3 ) surgically treated patients with no intervening stroke since the first PET examination; 4) availability and willingness of the patients to return for a PET examination after surgery; and 5) for symptomatic patients, a history of TIA or minor completed stroke in the ICA or MCA distribution. TIA was defined as focal symptoms of presumed ischemic cerebrovascular origin lasting $<24$
Table 1: Patient characteristics

\begin{tabular}{|c|c|c|c|}
\hline \multirow[b]{2}{*}{ Characteristic } & \multicolumn{2}{|c|}{$\begin{array}{c}\text { Surgically } \\
\text { Treated, } \\
\text { Misery Perfusion }\end{array}$} & \multirow{2}{*}{$\begin{array}{l}\text { Medically } \\
\text { Treatec } \\
\text { Yes }\end{array}$} \\
\hline & Yes & No & \\
\hline No. of patients & 9 & 9 & 8 \\
\hline Interval (mean) (mo) & $7 \pm 5$ & $6 \pm 4$ & $16 \pm 6^{a}$ \\
\hline $\begin{array}{l}\text { Interval from bypass to PET } \\
\text { (mean) (mo) }\end{array}$ & $6 \pm 4$ & $4 \pm 3$ & NA \\
\hline Age (yr) & $59 \pm 9$ & $59 \pm 13$ & $62 \pm 9$ \\
\hline Male sex (No.) & 7 & 5 & 7 \\
\hline Symptomatic (No.) & 8 & 8 & 6 \\
\hline Cerebral ischemic lesions (No.) & 8 & 9 & 7 \\
\hline \multicolumn{4}{|l|}{ Qualifying artery (No.) } \\
\hline ICA (occlusion/stenosis) & $8(8 / 0)$ & $6(4 / 2)$ & $5(5 / 0)$ \\
\hline MCA (occlusion/stenosis) & $1(0 / 1)$ & $3(3 / 0)$ & $3(3 / 0)$ \\
\hline \multicolumn{4}{|l|}{ Other medical illness (No.) } \\
\hline Hypertension & 6 & 7 & 3 \\
\hline Diabetes mellitus & 4 & 2 & 3 \\
\hline Ischemic heart disease & 5 & 2 & 3 \\
\hline Hypercholesterolemia & 5 & 1 & 3 \\
\hline $\begin{array}{l}\text { Smoking habit (current and } \\
\text { former) (No.) }\end{array}$ & 6 & 4 & 4 \\
\hline Antiplatelet agents & 9 & 9 & 7 \\
\hline Statins & 4 & 1 & 3 \\
\hline \multicolumn{4}{|l|}{ Postbypass: } \\
\hline TIA & 3 & 1 & NA \\
\hline Cerebral ischemic lesion & 2 & 0 & NA \\
\hline
\end{tabular}

hours. Exclusion criteria were the following: 1) cerebral-cortical, cerebellar, or brain stem infarct detectable on routine MR imaging (T1WI, T2WI, or FLAIR) or CT, 2) unilateral arterial disease with extensive white matter lesions in both hemispheres probably caused by bilateral small-vessel disease, 3 ) history of taking BZR agonists, and 4) the presence of potential sources of cardiogenic embolism.

Follow-up PET examinations were performed in 8 medically treated patients with MP at baseline (Table 1). They were selected from a cohort of a previously published follow-up PET study for 80 medically treated patients with stenosis or occlusion of the ICA or MCA and no intervening TIA or stroke. ${ }^{19}$ Criteria for selection were as follows: 1) occlusion of the extracranial ICA or occlusion or stenosis ( $>50 \%$ diameter reduction) of the intracranial ICA or MCA, and 2) MP at the baseline PET study. The interval between the first and follow-up PET studies ranged from 7 to 26 months (mean, $16 \pm 6$ months).

For vascular risk factors, the status of hypertension, diabetes mellitus, ischemic heart disease, hypercholesterolemia, and smoking was evaluated from patient histories recorded at the first PET examination. Hypertension, diabetes mellitus, ischemic heart disease, or hypercholesterolemia was judged to be present when there was a history of treatment.

To establish a control data base for BZR imaging, we studied 10 healthy control subjects ( 7 men and 3 women; mean age, $57 \pm$ 7 years) with no previous history of a medical or psychiatric disorder or of taking BZR agonists. Among them, 7 subjects (mean age, $56 \pm 8$ years, including 4 men and 3 women) underwent follow-up PET examinations. The interval between the first and follow-up PET studies ranged from 38 to 45 months (mean, $41 \pm$ 3 months). All protocols in this study were approved by the ethics 
committee of Shiga Medical Center, and all subjects gave written informed consent.

\section{PET Measurements}

PET scans were performed for each subject by using a whole-body PET scanner, GE Advance (GE Healthcare, Milwaukee, Wiscon$\sin$ ), which permits the simultaneous acquisition of 35 image sections with an intersection spacing of $4.25 \mathrm{~mm} \cdot{ }^{20}$ After a transmission scan by germanium-68/gallium-68, a series of ${ }^{15} \mathrm{O}$-gas studies was performed. ${ }^{20}$ Briefly, $\mathrm{C}^{15} \mathrm{O}_{2}$ and ${ }^{15} \mathrm{O}_{2}$ were delivered continuously to the patient via a mask for the duration of a 5-minute scan. $\mathrm{CBV}$ was measured by bolus inhalation of $\mathrm{C}^{15} \mathrm{O}$ with scanning for 3 minutes. Arterial samples were obtained during scanning. No subject showed substantial changes in the partial pressure of carbon dioxide in arterial blood during scanning.

The ${ }^{15} \mathrm{O}$-gas study was followed by a study of ${ }^{11} \mathrm{C}$-flumazenil, ${ }^{16,21}$ which was synthesized by ${ }^{11} \mathrm{C}$-methylation of demethylated-flumazenil (FMZ) (Hoffmann-La Roche, Basel, Switzerland). After the slow intravenous injection of ${ }^{11} \mathrm{C}-\mathrm{FMZ}$, a 50-minute dynamic PET scan was initiated.

We used the steady-state method to calculate CBF, the cerebral metabolic rate of oxygen $\left(\mathrm{CMRO}_{2}\right)$, and $\mathrm{OEF} .{ }^{22}$ The $\mathrm{CMRO}_{2}$ and $\mathrm{OEF}$ were corrected on the basis of $\mathrm{CBV}$. The binding potential (nondisplaceable) of ${ }^{11} \mathrm{C}$-flumazenil was calculated by using dynamic data and Logan graphic analysis with reference tissue, with the pons as the reference region. ${ }^{21,23}$

\section{Data Analysis}

For ${ }^{15} \mathrm{O}$-gas PET scanning analysis, we used a classic ROI analysis. We analyzed 10 tomographic planes, located $46.25-84.5 \mathrm{~mm}$ above and parallel to the orbitomeatal line. ${ }^{24}$ The lowest plane corresponded to the level of the basal ganglia and the thalamus, and the uppermost plane corresponded to the level of the centrum semiovale. An ROI was selected for CBF images. Each image was examined by compactly placing 10-12 circular ROIs (diameter, $16 \mathrm{~mm}$ ) over the gray matter of the outer cortex in each hemisphere. According to the atlas, ${ }^{25}$ the ROIs in all 10 images covered the distribution of the MCA and the external borderzone regions. ${ }^{24,25}$ The same ROIs were used for the $\mathrm{CMRO}_{2}, \mathrm{OEF}$, and $\mathrm{CBV}$ images. The mean hemispheric value for the hemisphere affected by ICA or MCA disease was calculated as the average of all the circular ROIs.

Normal control values of the PET variables were obtained from 7 healthy volunteers ( 4 men and 3 women; mean age, $47 \pm 7$ years) who underwent routine neurologic examinations and MR imaging. The mean OEF value in the 14 control hemispheres was $44.5 \% \pm 3.8 \%$. Hemispheric OEF values beyond the upper $95 \%$ limit defined in healthy subjects $(>52.9 \%)$ were considered to represent increased OEF. Comparative values for $\mathrm{CBF}$ and $\mathrm{CBF} /$ CBV in healthy volunteers were $44.6 \pm 4.5 \mathrm{~mL} / 100 \mathrm{~g} / \mathrm{min}$ and $11.4 \pm 1.8 / \mathrm{min}$, respectively. Hemispheric CBF and CBF/CBV values below $35.0 \mathrm{~mL} / 100 \mathrm{~g} / \mathrm{min}$ and $7.6 / \mathrm{min}$, respectively, were considered abnormal. Patients with increased OEF, decreased $\mathrm{CBF}$, and decreased CBF/CBV in hemispheres with arterial disease were categorized as having MP. ${ }^{4}$ One investigator unaware of the clinical status categorized the patients.

Flumazenil-binding potential parametric images were ana- lyzed by using a 3D-stereotactic surface-projection technique, as previously described. ${ }^{16,26}$ This technique anatomically normalizes individual PET data to a standard brain and compares regional voxel data between patients and controls. In the standard stereotactic system, pixels located on the outer and medial surfaces of both hemispheres and vectors perpendicular to the $3 \mathrm{D}$ surface at each pixel are predetermined. For each predetermined surface pixel on an individual's anatomically standardized PET image set, the algorithm searches along the vector, 6 pixels deep into the cortex, for the highest pixel value and assigns this maximum value to the surface pixel. To correct for fluctuations in whole-brain values and to extract the changes due to ICA or MCA disease, we normalized the pixel values of an individual's image set to the mean cerebellar value before analysis. $Z$ scores were calculated for each surface pixel as (Mean Normalized Pixel Value for Controls - Normalized Pixel Value for the Patient) / (SD for controls), and were used to quantify decreases in flumazenilbinding potential (FMZ-BP). Thus, a positive $z$ score in a patient represented reduced FMZ-BP relative to the control group. An increased BZR index corresponded to a decreased BZR level, a decreased FMZ-BP level, and thus greater cortical neural damage.

To quantify the degree of abnormal flumazenil-binding potential reduction in each patient, we used the stereotactic extraction estimation method to calculate a BZR index, defined as (\% Pixels with $z$ Score $>2 \times$ Average $z$ score for those pixels) for the cerebral-cortical MCA distribution affected by ICA or MCA disease. $^{27}$ This MCA distribution included the middle and inferior frontal gyri; the precentral gyrus; the superior and inferior parietal gyri; the angular, postcentral, and supramarginal gyri; the superior, middle, inferior, and transverse temporal gyri; and the superior and middle occipital gyri. ${ }^{27}$

At postsurgical or follow-up examinations, total change in the $\mathrm{BZR}$ index or the $\mathrm{CBF}, \mathrm{CMRO}_{2}, \mathrm{OEF}, \mathrm{CBV}$, or $\mathrm{CBF} / \mathrm{CBV}$ values in the MCA distribution with arterial disease was calculated by subtracting the values obtained at the second examination from those obtained at the first examination. In controls, the calculation was performed by using the mean of the bilateral hemispheric values of the BZR index. The mean value of changes in the index in the controls was $0.94 \pm 1.38$. In patients, an increase of the index beyond the upper $95 \%$ limit (the mean plus $6 \mathrm{t} 0.05 \times \mathrm{SD} ; 6 \mathrm{t} 0.05$, the value of $\mathrm{t}$ for $P<0.05$ and degree of freedom $=6$ ) defined in healthy subjects $(>4.32)$ was considered an increased BZR index (progression of neuronal damage) during follow-up. ${ }^{16}$

\section{Statistical Analysis}

The statistical analysis was performed by using StatView (SAS Institute, Cary, North Carolina). Comparisons of clinical backgrounds or PET values among the 3 groups were performed with 1-way ANOVA and a post hoc Scheffe analyses or Kruskal-Wallis tests and post hoc Mann-Whitney $U$ tests as appropriate. PET variable values were compared between examinations by using paired $t$ tests. Relationships between variables were analyzed by using simple or multiple regression analyses. A multivariable linear regression model with a forward stepwise selection procedure was used to test the independent predictive value of the presence of MP at baseline and the change in PET variables during fol- 
Table 2: PET variables for surgically or medically treated patients ${ }^{\mathrm{a}}$

\begin{tabular}{|c|c|c|c|}
\hline Characteristic, MP & $\begin{array}{l}\text { Surgical, Yes } \\
\quad(n=9)\end{array}$ & $\begin{array}{l}\text { Surgical, No } \\
(n=9)\end{array}$ & $\begin{array}{c}\text { Medical, Yes } \\
\quad(n=8)\end{array}$ \\
\hline \multicolumn{4}{|l|}{ Baseline } \\
\hline BZR index & $53.1 \pm 45.4$ & $35.5 \pm 32.2$ & $53.2 \pm 39.8$ \\
\hline $\mathrm{CBF}(\mathrm{mL} / 100 \mathrm{~g} / \mathrm{min})$ & $27.9 \pm 4.1^{\mathrm{b}}$ & $34.8 \pm 4.1$ & $25.8 \pm 6.6^{b}$ \\
\hline $\mathrm{CMRO}_{2}(\mathrm{~mL} / 100 \mathrm{~g} / \mathrm{min})$ & $2.73 \pm 0.60$ & $3.19 \pm 0.35$ & $2.69 \pm 0.47$ \\
\hline OEF $(\%)$ & $59.9 \pm 4.0$ & $54.4 \pm 4.3$ & $60.1 \pm 6.0$ \\
\hline $\mathrm{CBV}(\mathrm{mL} / 100 \mathrm{~g})$ & $4.41 \pm 1.08$ & $3.96 \pm 0.84$ & $3.81 \pm 0.90$ \\
\hline $\mathrm{CBF} / \mathrm{CBV}\left(\mathrm{min}^{-1}\right)$ & $6.48 \pm 0.97$ & $9.08 \pm 1.92$ & $6.82 \pm 0.83$ \\
\hline \multicolumn{4}{|l|}{ Follow-up } \\
\hline BZR index & $80.7 \pm 57.2$ & $30.3 \pm 26.8$ & $56.4 \pm 39.8$ \\
\hline $\mathrm{CBF}(\mathrm{mL} / 100 \mathrm{~g} / \mathrm{min})$ & $32.7 \pm 5.5$ & $34.0 \pm 5.7$ & $28.5 \pm 6.6$ \\
\hline $\mathrm{CMRO}_{2}(\mathrm{~mL} / 100 \mathrm{~g} / \mathrm{min})$ & $2.94 \pm 0.67$ & $3.14 \pm 0.39$ & $2.82 \pm 0.45$ \\
\hline OEF (\%) & $56.4 \pm 5.5$ & $55.8 \pm 7.3$ & $55.9 \pm 6.1$ \\
\hline $\mathrm{CBV}(\mathrm{mL} / 100 \mathrm{~g})$ & $4.15 \pm 1.03$ & $3.74 \pm 0.59$ & $3.72 \pm 1.01$ \\
\hline $\mathrm{CBF} / \mathrm{CBV}\left(\mathrm{min}^{-1}\right)$ & $8.31 \pm 2.28$ & $9.31 \pm 2.21$ & $7.77 \pm 0.78$ \\
\hline BZR index change & $27.5 \pm 15.6^{c}$ & $-5.2 \pm 9.4$ & $3.2 \pm 15.4$ \\
\hline CBF change (mL/100 g/min) & $4.81 \pm 4.02^{b}$ & $-0.77 \pm 4.23$ & $2.67 \pm 3.59$ \\
\hline $\mathrm{CMRO}_{2}$ change $(\mathrm{mL} / 100 \mathrm{~g} / \mathrm{min})$ & $0.21 \pm 0.35$ & $-0.05 \pm 0.49$ & $0.13 \pm 0.28$ \\
\hline OEF change (\%) & $-3.42 \pm 4.62$ & $1.36 \pm 5.15$ & $-4.26 \pm 3.68$ \\
\hline CBV change $(\mathrm{mL} / 100 \mathrm{~g})$ & $-0.26 \pm 1.40$ & $-0.21 \pm 0.68$ & $-0.09 \pm 0.51$ \\
\hline $\mathrm{CBF} / \mathrm{CBV}$ change $\left(\mathrm{min}^{-1}\right)$ & $1.83 \pm 2.01$ & $0.23 \pm 1.56$ & $0.95 \pm 1.35$ \\
\hline
\end{tabular}

${ }^{a}$ Reference values for BZR index, $\mathrm{CBF}, \mathrm{CMRO}_{2}, \mathrm{OEF}, \mathrm{CBV}$, and $\mathrm{CBF} / \mathrm{CBV}$ were $1.78 \pm 1.79,44.6 \pm 4.5,3.43 \pm 0.33,44.5 \pm$ 3.8, $3.98 \pm 0.48$, and $11.4 \pm 1.8$, respectively. Data are means.

${ }^{\mathrm{b}} \mathrm{P}<.05$ vs no group.

c $P<.001$ vs no group and $P<.01$ vs medical group.

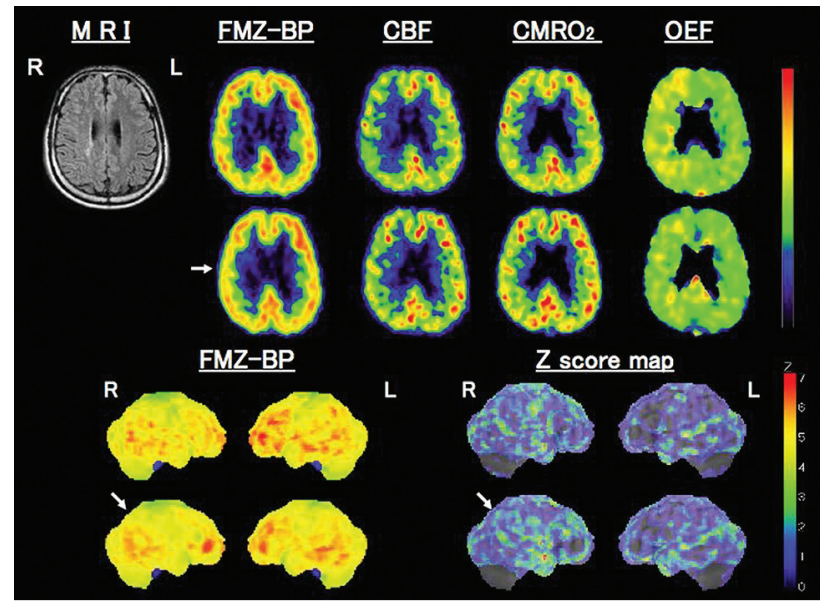

FIG 1. Representative images of ${ }^{11} \mathrm{C}$-flumazenil PET showing decreased BZR levels in a patient with right ICA occlusion and misery perfusion. The first PET study (first row) shows a mild decrease in the flumazenil-binding potential in the right $(\mathrm{R})$ hemisphere with ICA occlusion and subcortical or deep white matter ischemic lesions (MR imaging) in which CBF is decreased and the oxygen extraction fraction is increased (misery perfusion). Follow-up 16 months later (second row) (15 months after bypass to the frontal branch of the MCA) shows relative decreases in FMZ-BP (arrow) and OEF, with increased CBF in the right hemisphere. 3D-stereotactic surface projection images and $z$ score maps from the first (third row) and second (fourth row) examinations demonstrate a decrease in FMZ-BP in the right MCA distribution, especially in the parietotemporal lobe (arrow). The BZR index is increased from 71.6 to 100.8 between baseline and follow-up (arrow). An increased BZR index corresponds to a decreased BZR level, a decreased FMZ-BP level, and thus greater cortical neural damage. An increased BZR index was apparent in the cortical regions outside the territory of the recipient vessel, which suggested that cortical neural damage could not be ascribed to technical problems of the bypass anastomosis or postoperative hyperperfusion and might be associated with sustained hemodynamic impairment. low-up with respect to the change in the BZR index. For all analyses, statistical significance was defined as $P<.05$.

\section{RESULTS}

Four of the 18 patients who underwent bypass surgery had TIA after surgery. Two patients showed new small subcortical high-intensity lesions on follow-up MR images. Bypass was patent at follow-up in all patients on MRA.

Before the operation, 9 patients $(50 \%)$ with increased OEF, decreased $\mathrm{CBF}$, and decreased $\mathrm{CBF} / \mathrm{CBV}$ in hemispheres with arterial disease were categorized as having MP. No patient characteristics significantly differed between the patients with MP and those without it (Table 1). The value of the BZR index at baseline was not different between the 2 groups (Table 2).

After the operation, patients with MP showed a significant increase in the BZR index (paired $t$ test, $P<.001$ ), CBF $(P<.01)$, and $\mathrm{CBF} / \mathrm{CBV}(P<.05)$ and a tendency toward decreases in the $\operatorname{OEF}(P=.06)$, while patients without MP did not show significant changes in any PET variables (Table 2 and Fig 1 ). The BZR index in the MP group tended to be larger $(P=.07)$ than that in the no-MP group after the operation.

The change in the BZR index in the MP group was significantly larger than that in the no-MP group $(P<.001)$. Eight patients $(89 \%)$ with MP showed an increase in the BZR index beyond the upper $95 \%$ limit defined in healthy subjects, while no patients without MP $(0 \%)$ showed increases in the BZR index (Fisher exact test, $P=.0004)$. The change in the BZR index was significantly correlated with the value of $\mathrm{CBF}(r=-0.66, P<.005)$ or OEF $(r=0.47, P<.05)$ at baseline (Fig 2).

A multivariable linear regression analysis (forward stepwise selection) was used to investigate the association of changes in the BZR index with the following: 1) the presence of MP at baseline; 2) changes in the values of $\mathrm{CBF}, \mathrm{CMRO}_{2}, \mathrm{OEF}, \mathrm{CBV}$, or $\mathrm{CBF} / \mathrm{CBV}$ after bypass; 3 ) the presence of vascular risk factors; and 4) drugtreatment history (Table 1). Our analysis produced a model that included the presence of MP at baseline, changes in the OEF after surgery, and smoking habit, with a correlation coefficient of 0.905 for the changes in the BZR index after surgery $(P<.001)$. In our model, the presence of MP, changes in the OEF, and smoking habit accounted for $64.5 \%, 8.2 \%$, and $9.2 \%$ of the variance in changes in the BZR index, respectively. The presence of MP (coefficient, 35.2; standard error, $5.2 ; t=6.7 ; P<.0001$ ), changes in the OEF (coefficient, 1.2 ; standard error, $0.5 ; t=2.5 ; P<.05$ ), and smoking habit (coefficient, 13.3; standard error, $4.7 ; t=2.7 ; P<$ $.05)$ were positively correlated with changes in the BZR index.

Eight medically treated patients with MP showed a longer interval $(P<.05)$ between the 2 PET examinations than 9 surgically treated patients with MP (Table 1). Other patient characteristics were not significantly different between the medically and surgi- 

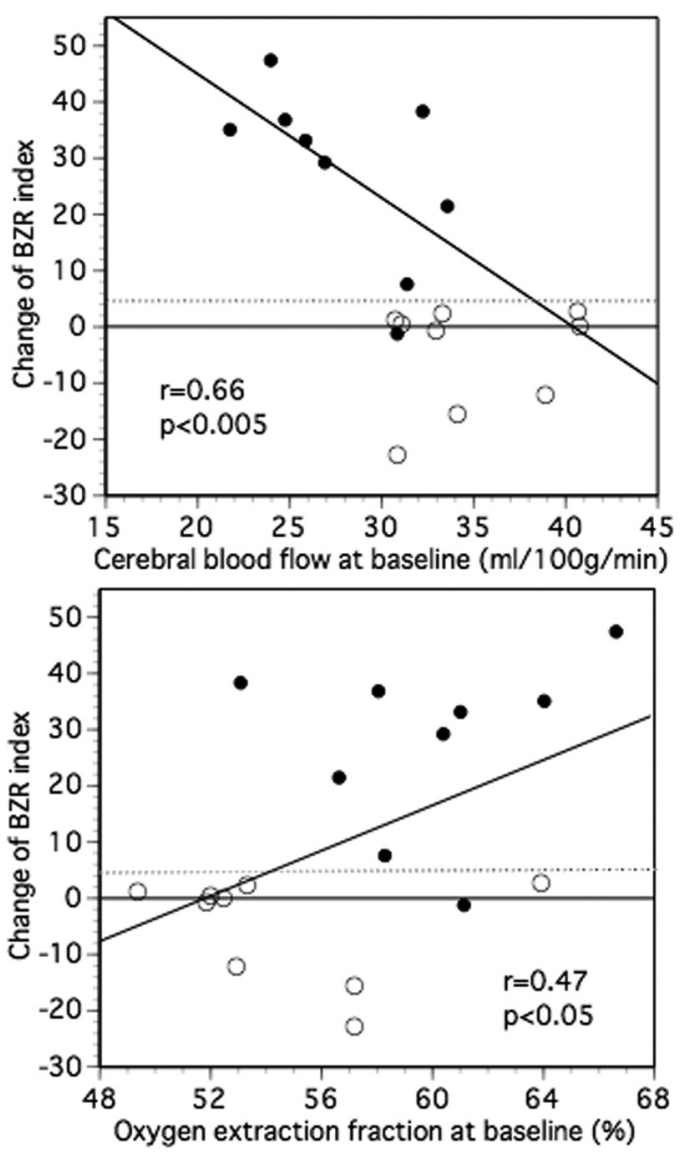

FIG 2. Scatterplots of changes in the BZR index in 18 surgically treated patients and the mean hemispheric CBF at baseline (upper row) or the mean hemispheric OEF at baseline (lower row) in the hemisphere with arterial disease. The dashed lines show the upper 95\% limit of changes in the BZR index for the 7 controls. The closed circles indicate patients with misery perfusion, and the open circles indicate patients without misery perfusion.

cally treated patients with MP, though medically treated patients had no intervening TIA. The values of the BZR index and other PET variables at baseline or at follow-up were not significantly different between the 2 groups, while at follow-up, the BZR index in the surgically treated patients with MP had a tendency to be larger $(P=.07)$ than that in the medically treated patients. The change in the BZR index in surgically treated patients was significantly larger than that in medically treated patients $(P<.01)$. Three medically treated patients $(37 \%)$ and 8 surgically treated patients $(89 \%)$ showed an increase in the BZR index beyond the upper 95\% limit defined in healthy subjects (Fisher exact test, $P<$ $.05)$. At follow-up, 3 surgically treated patients and 1 medically treated patient showed MP (Fisher exact test, $P=.57$ ).

\section{DISCUSSION}

This study demonstrates that the progression of cortical neuronal damage manifests as a decrease in BZRs in the normal-appearing cerebral cortex of surgically treated patients with MP and no perioperative stroke. The degree of progressive cortical neuronal damage in surgically treated patients with MP was significantly larger than that in medically treated patients with MP and no intervening ischemic event.

The precise reason for the progression of cortical neuronal damage in surgically treated patients with MP and no perioperative stroke is unclear from the present study. However, perioperative ischemia, postoperative hyperperfusion, and hemodynamic ischemia during follow-up might cause cortical neuronal damage. In patients with MP, the risk for perioperative ischemic events is reported to be high. ${ }^{28,29}$ Patients with MP have a marginally adequate blood supply relative to metabolic demand, which increases the risk of cerebral ischemia. ${ }^{1,3,4}$ Therefore, it is reasonable to hypothesize that fluctuations of cerebral hemodynamics during perioperative periods might have caused ischemic neuronal damage in surgically treated patients with MP. Additionally, the presence of MP is reported to be a risk factor for postoperative hyperperfusion after bypass. ${ }^{29}$ Cerebral hyperperfusion after carotid endarterectomy was found to result in a decrease in BZRs. ${ }^{17}$ To prevent perioperative neuronal damage, therapeutic strategies that limit selective neuronal damage, including careful perioperative management ${ }^{30}$ and the use of neuroprotective agents, ${ }^{31,32}$ may be needed for patients with MP. Furthermore, MP may not improve completely or immediately after bypass surgery. Thus, the risk for hemodynamic ischemia may persist during follow-up.

The progression of cortical neuronal damage in surgically treated patients with MP was larger than that in medically treated patients with MP and no intervening ischemic event. Surgically treated patients with MP showed an expected increase in $\mathrm{CBF}$ and $\mathrm{CBF} / \mathrm{CBV}$ and a tendency for decreased OEF at postsurgical examinations, indicating hemodynamic improvement. We found that decreases in the OEF after bypass were associated with smaller increases in the BZR index after bypass. Therefore, successful bypass surgery might have reduced the risk of neuronal damage in surgically treated patients thereafter. On the other hand, medically treated patients with MP and no intervening ischemic event also showed hemodynamic improvement of a similar degree, which may be due to long-term improvement of collateral blood flow. Medically treated patients with MP have a high risk for subsequent ischemic stroke. ${ }^{4,9}$ However, if they are successfully treated and have no intervening ischemic event, the risk for ischemic damage could be reduced. Medical treatment may play an important role in preventing progressive neuronal damage. ${ }^{19}$ If we use BZR decreases as objective markers of neuronal damage, our findings do not support the hypothesis that bypass surgery is superior to medical therapy in patients with MP.

The Randomized Evaluation of Carotid Occlusion and Neurocognition trial failed to show that bypass can improve cognition during 2 years compared with optimal medical therapy alone in patients with symptomatic ICA occlusion and MP. ${ }^{8}$ On the basis of the findings in the present study, we could not completely exclude the possibility that bypass surgery for patients with MP may have induced selective cortical neuronal damage that overshadowed the beneficial effects of improved cerebral perfusion. Post hoc analysis in the trial showed that cognitive improvement was associated with a less impaired PET OEF at baseline. As shown in the present study, patients with a less impaired OEF might have less perioperative neuronal damage, which, in turn, may have allowed cognitive improvement.

The findings in the present study have some implications for treatment selection and potential clinical outcomes. Reperfusion therapies could be most beneficial for patients with hemodynamic 
impairment to improve clinical outcomes. However, reperfusion therapies may have a risk of neuronal damage for patients with hemodynamic impairment. Carotid endarterectomy and bypass surgery for patients with chronic hemodynamic impairment may be associated with cortical neuronal damage that may be correlated with postoperative cognitive impairment. ${ }^{17}$ In acute stroke, selective neuronal damage may affect salvaged penumbra and hamper functional recovery following reperfusion. ${ }^{12}$ The progression of cortical neuronal damage should be considered while treating patients with hemodynamic impairment by means of reperfusion therapy.

\section{Limitations}

This study had certain limitations, including a small sample size and a cohort with both ICA and MCA disease. It also retrospectively analyzed data from a prospective observational study. Therefore, there is a considerable risk of selection bias, though the clinical backgrounds were not significantly different among the 3 groups. For these reasons, the findings in this study should be confirmed in future randomized and blinded studies. The selection of bypass surgery was left to individual clinical judgment by attending physicians, and unknown clinical factors could have swayed treatment decisions. Nine patients with less marked hemodynamic impairment than is indicative of MP underwent bypass surgery due to regional increases in OEF in addition to other characteristics (poor collateral pathways or recurrent symptoms). Additionally, 2 patients with perioperative stroke were excluded from analysis. One patient with MP had progressing stroke after the first PET examination and underwent emergency bypass surgery, and another without MP showed multiple MR imaging lesions after aneurysm treatment performed in combination with bypass surgery. The interval time between baseline and follow-up PET for medically treated patients with MP was twice as long as that for surgically treated patients with MP, which may make it difficult to accurately compare patient groups. However, the longer interval may lead to the larger, not smaller, increase of cortical neuronal damage in medically treated patients, which may not change the conclusion. The period of patient recruitment ranged from 2002 to 2013, but the PET scan protocol had not changed, so it likely offered the same precision and accuracy. We could not systematically investigate cognitive differences among these patients. Although decreases in BZRs are objective markers of neuronal injury that may be associated with cognitive impairment, ${ }^{12,17,33}$ the functional effect of neuronal damage should have been determined by neuropsychological testing.

\section{CONCLUSIONS}

The progression of cortical neuronal damage manifests as a decrease in BZRs in the normal-appearing cerebral cortex of surgically treated patients with MP and no perioperative stroke. The degree of progressive cortical neuronal damage in surgically treated patients with MP may be larger than that in medically treated patients with MP and no intervening ischemic event. The progression of cortical neuronal damage should be considered while treating patients with MP with bypass surgery.

\section{REFERENCES}

1. Baron JC, Bousser MG, Rey A, et al. Reversal of focal "misery-perfusion syndrome" by extra-intracranial arterial bypass in hemodynamic cerebral ischemia: a case study with ${ }^{15} \mathrm{O}$ positron emission tomography. Stroke 1981;12:454-59 CrossRef Medline

2. Klijn CJ, Kappelle LJ. Haemodynamic stroke: clinical features, prognosis, and management. Lancet Neurol 2010;9:1008-17 CrossRef Medline

3. Powers WJ. Cerebral hemodynamics in ischemic cerebrovascular disease. Ann Neurol 1991;29:231-40 CrossRef Medline

4. Yamauchi $\mathrm{H}$, Higashi $\mathrm{T}$, Kagawa $\mathrm{S}$, et al. Is misery perfusion still a predictor of stroke in symptomatic major cerebral artery disease? Brain 2012;135:2515-26 CrossRef Medline

5. Marshall RS, Festa JR, Cheung YK, et al. Cerebral hemodynamics and cognitive impairment: baseline data from the RECON trial. Neurology 2012;78:250-55 CrossRef Medline

6. Powers WJ, Martin WRW, Herscovitch P, et al. Extracranial-intracranial bypass surgery: hemodynamic and metabolic effects. $\mathrm{Neu}$ rology 1984;34:1168-74 CrossRef Medline

7. JET Study Group. Japanese EC-IC Bypass Trial (JET study): the second interim analysis. Surgery for Cerebral Stroke 2002;30:434-37 CrossRef

8. Marshall RS, Festa JR, Cheung YK, et al; RECON Investigators. Randomized Evaluation of Carotid Occlusion and Neurocognition (RECON) trial: main results. Neurology 2014;82:744-51 CrossRef Medline

9. Powers WJ, Clarke WR, Grubb RL Jr, et al; COSS Investigators. Extracranial-intracranial bypass surgery for stroke prevention in hemodynamic cerebral ischemia: the Carotid Occlusion Surgery Study randomized trial. JAMA 2011;306:1983-92 CrossRef Medline

10. Sasoh M, Ogasawara K, Kuroda K, et al. Effects of EC-IC bypass surgery on cognitive impairment in patients with hemodynamic cerebral ischemia. Surg Neurol 2003;59:455-60; discussion 460-63 CrossRef Medline

11. Jacobs BS, Nichols FT 3rd. Does improving misery cerebral perfusion improve misery cognition? Neurology 2014;82:738-39 CrossRef Medline

12. Baron JC, Yamauchi H, Fujioka M, et al. Selective neuronal loss in ischemic stroke and cerebrovascular disease. J Cereb Blood Flow Metab 2014;34:2-18 CrossRef Medline

13. Heiss WD, Grond M, Thiel A, et al. Permanent cortical damage detected by flumazenil positron emission tomography in acute stroke. Stroke 1998;29:454-61 CrossRef Medline

14. Sette G, Baron JC, Young AR, et al. In vivo mapping of brain benzodiazepine receptor changes by positron emission tomography after focal ischemia in the anesthetized baboon. Stroke 1993;24:2046-57; discussion 2057-58 CrossRef Medline

15. Ejaz S, Williamson DJ, Ahmed T, et al. Characterizing infarction and selective neuronal loss following temporary focal cerebral ischemia in the rat: a multi-modality imaging study. Neurobiol Dis 2013;51: 120-32 CrossRef Medline

16. Yamauchi H, Kudoh T, Kishibe Y, et al. Selective neuronal damage and chronic hemodynamic cerebral ischemia. Ann Neurol 2007;61: 454-65 CrossRef Medline

17. Chida K, Ogasawara K, Suga Y, et al. Postoperative cortical neural loss associated with cerebral hyperperfusion and cognitive impairment after carotid endarterectomy: 123I-iomazenil SPECT study. Stroke 2009;40:448-53 CrossRef Medline

18. Samuels OB, Joseph GJ, Lynn MJ, et al. A standardized method for measuring intracranial arterial stenosis. AJNR Am J Neuroradiol 2000;21:643-46 Medline

19. Yamauchi H, Kagawa S, Kishibe Y, et al. Progressive cortical neuronal damage and chronic hemodynamic impairment in atherosclerotic major cerebral artery disease. Stroke 2016;47:1534-41 CrossRef Medline

20. Okazawa H, Yamauchi H, Sugimoto K, et al. Quantitative comparison of the bolus and steady-state methods for measurement of cerebral perfusion and oxygen metabolism: positron emission 
tomography study using $\mathbf{1 5 0}$ gas and water. J Cereb Blood Flow Metab 2001;21:793-803 Medline

21. Okazawa H, Yamauch H, Sugimoto K, et al. Effects of metabolite correction for arterial input function on quantitative receptor images with $11 \mathrm{C}$-flumazenil in clinical positron emission tomography studies. J Comput Assist Tomogr 2004;28:428-35 CrossRef Medline

22. Frackowiak RS, Lenzi GL, Jones T, et al. Quantitative measurement of regional cerebral blood flow and oxygen metabolism in man using ${ }^{15} \mathrm{O}$ and positron emission tomography: theory, procedure, and normal values. J Comput Assist Tomogr 1980;4:727-36 CrossRef Medline

23. Logan J, Fowler JS, Volkow ND, et al. Distribution volume ratios without blood sampling from graphical analysis of PET data. J Cereb Blood Flow Metab 1996;16:834-40 Medline

24. Yamauchi H, Fukuyama H, Kimura J, et al. Hemodynamics in internal carotid artery occlusion examined by positron emission tomography. Stroke 1990;21:1400-06 CrossRef Medline

25. Kretschmann HJ, Weinrich W. Neuroanatomy and Cranial Computed Tomography. New York: Thieme; 1986:70-74

26. Minoshima S, Frey KA, Koeppe RA, et al. A diagnostic approach in Alzheimer's disease using three-dimensional stereotactic surface projections of fluorine-18-FDG PET. J Nucl Med 1995;36:1238-48 Medline

27. Mizumura S, Kumita S, Cho K, et al. Development of quantitative analysis method for stereotactic brain image: assessment of re- duced accumulation in extent and severity using anatomical segmentation. Ann Nucl Med 2003;17:289-95 CrossRef Medline

28. Gibbs JM, Wise RJS, Thomas DJ, et al. Cerebral haemodynamic changes after extracranial-intracranial bypass surgery. J Neurol Neurosurg Psychiatry 1987;50:140-50 CrossRef Medline

29. Yamaguchi K, Kawamata T, Kawashima A, et al. Incidence and predictive factors of cerebral hyperperfusion after extracranial-intracranial bypass for occlusive cerebrovascular diseases. Neurosurgery 2010;67:1548-54; discussion 1554 CrossRef Medline

30. Kuroda S, Kawabori M, Hirata K, et al. Clinical significance of STAMCA double anastomosis for hemodynamic compromise in postJET/COSS era. Acta Neurochir (Wien) 2014;156:77-83 CrossRef Medline

31. Fujimura M, Niizuma K, Inoue $T$, et al. Minocycline prevents focal neurological deterioration due to cerebral hyperperfusion after extracranial-intracranial bypass for Moyamoya disease. Neurosurgery 2014;74:163-70; discussion 170 CrossRef Medline

32. Uchino H, Nakayama N, Kazumata K, et al. Edaravone reduces hyperperfusion-related neurological deficits in adult Moyamoya disease: historical control study. Stroke 2016;47:1930-32 CrossRef Medline

33. Yamauchi H, Nishii R, Higashi T, et al. Selective neuronal damage and Wisconsin Card Sorting Test performance in atherosclerotic occlusive disease of the major cerebral artery. J Neurol Neurosurg Psychiatry 2011;82:150-56 CrossRef Medline 